
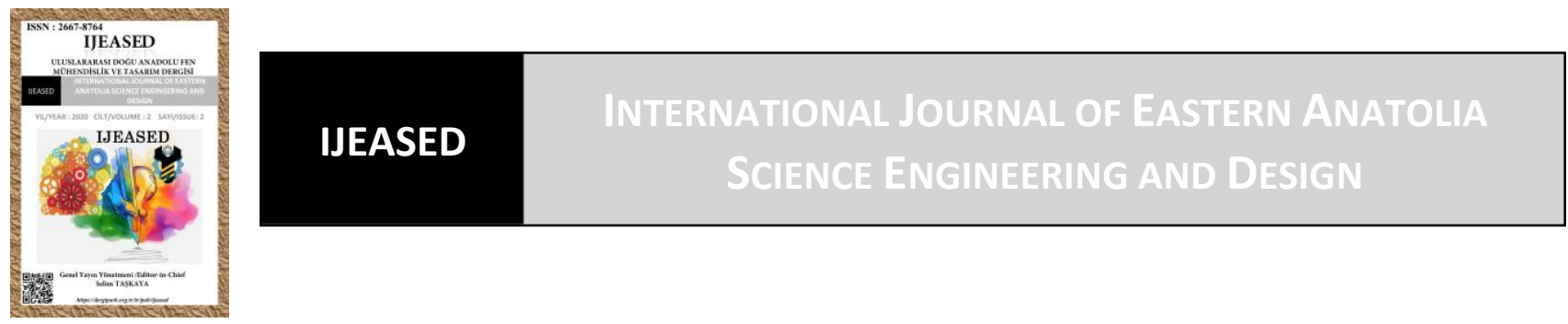

\author{
Uluslararası Doğu Anadolu Fen Mühendislik ve Tasarım Dergisi \\ ISSN: 2667-8764, 2(2), 296-307, 2020 \\ https://dergipark.org.tr/tr/pub/ijeased
}

Derleme Makalesi / Review Article

Doi: $\underline{10.47898 / \text { ijeased.757100 }}$

\title{
Doğu Karadeniz Bölgesindeki Hidroelektrik Santrallerin (HES) Kapasite Faktörlerinin Değerlendirilmesi
}

\author{
Esin ACAR *
}

Artvin Çoruh Üniversitesi, Borçka Acarlar MYO, İnşaat Bölümü, Artvin, 08000, Türkiye.

\begin{tabular}{l|ll|l}
\hline \multicolumn{1}{c|}{ Yazar Kimliği / Author ID (ORCID Number) } & \multicolumn{1}{|c}{ Makale Süreci / Article Process } \\
\hline *Sorumlu Yazar / Corresponding author : & Geliş Tarihi / Received Date $:$ & 24.06 .2020 \\
esin.acar@ artvin.edu.tr & Revizyon Tarihi / Revision Date : & 06.09 .2020 \\
\hline iD https://orcid.org/0000-0002-3926-2804, E. Acar & Kabul Tarihi / Accepted Date : & 17.10 .2020 \\
\hline & Yayım Tarihi / Published Date : & 15.12 .2020 \\
\hline
\end{tabular}

Alıntı /Cite : Acar, E. (2020). Doğu Karadeniz Bölgesindeki Hidroelektrik Santrallerin (HES) Kapasite Faktörlerinin Değerlendirilmesi, Uluslararası Doğu Anadolu Fen Mühendislik ve Tasarım Dergisi, 2(2), 296-307.

\begin{abstract}
Özet
Ülkemiz su potansiyeli açısından dünyada önemli bir yere sahip olup, farklı bölgelerinde Baraj Hidroelektrik Santraller yer almaktadır. Doğu Karadeniz Bölgesi de Türkiye'de önemli bir su potansiyeline sahiptir. Bu potansiyel enerji üretimi, taşkın koruma, içme suyu, sulama gibi çeşitli maksatlara hizmet veren baraj projeleri sayesinde hayat bulmaktadır. Özellikle Baraj Hidroelektrik Santralleri (HES) Türkiye'de ve hatta dünyada önemli bir konuma sahiptir. Faklı amaçlara hizmet edebilen barajlar bu bölgede özellikle enerji üretimi bakımından önem kazanmaktadır. Üretilen enerji miktarları ve kurulu güçleri bakımından Doğu Karadeniz Bölgesi ülkemizin sayılı Baraj HES projelerini barındırmaktadır. Bu kapasitede olmalarının en önemli etkisi su potansiyelinin yüksek olmasıdır. Baraj enerji üretimini etkileyen en önemli parametrelerden birisi kurulu güç (K.G.) kapasiteleri ve üretilen ortalama enerji miktarlarıdır. Bu parametreler ile Baraj HES projelerinin kapasite faktörleri projelerinin yapılabilirlikleri açısından önemlidir. Kapasite faktörü; enerji santralinin belli bir zaman aralığında ürettiği toplam enerji miktarının, tam kapasitede üretebileceği enerji miktarına olan oranıdır. Bu faktör projenin ekonomik, teknik ve fizibilite değerlendirmelerinde dikkate alınması gereken bir değerdir. Bu çalışma ile coğrafi olarak Doğu Karadeniz Bölgesinde yer alan Baraj HES projeleri değerlendirilmiştir. Bu projelerin kurulu güç ve enerji üretim değerleri elde edilerek, kapasite faktörleri belirlenmiş ve projeler arasında karşıllaştırmalar yapılmıştır. Böylece teknik değerlendirme kriterlerinden birisi olan kapasite faktörünün önemi vurgulanarak, ortaya çıkan sonuçlar tartışılmıştır.
\end{abstract}

Anahtar Kelimeler: Baraj HES, Kapasite faktörü, Kurulu güç, Enerji üretimi. 


\title{
Determination Of The Capacity Factors Of Dam Hydroelectric Power Plants (HEPP) In Eastern Black Sea Region
}

\begin{abstract}
There are different Dam Hydroelectric Power Plants in various regions of our country. Eastern Black Sea Region also has significant water potential in Turkey. This potential comes to life thanks to dam projects serving various purposes such as energy production, flood protection, drinking water and irrigation. Especially Dam Hydroelectric Power Plants (HPP) has an important position in the world and even Turkey. The dams that can serve different purposes gain importance in this region especially in terms of energy production. In terms of the energy produced and installed powers, the Eastern Black Sea Region hosts the numbered Dam HEPP projects of our country. The most important effect of these capacities is the high water potential. One of the most important parameters affecting dam energy production is installed power $(G G)$ capacities and average energy produced. With these parameters, capacity factors of Baraj HEPP projects are important for the feasibility of projects. Capacity factor; is the ratio of the total amount of energy produced by the power plant in a certain period of time to the amount of energy it can produce at full capacity. This factor is a value that should be taken into account in the economic, technical and feasibility assessments of the project. With this study, the Dam HEPP projects located in the Eastern Black Sea Region were evaluated geographically. The installed power and energy production values of these projects were obtained, capacity factors were determined and comparisons were made between the projects. Thus, the importance of the capacity factor, which is one of the technical evaluation criteria, was emphasized and the results were discussed.
\end{abstract}

Keywords: Dam HEPP, Capacity factor, Installed capacity, Energy production.

\section{Giriş}

Çevre sorunlarının başında enerji üretmek amacıyla kullanılan santraller gelmektedir. Özellikle yenilenebilir olmayan (termik, doğalgaz, nükleer gibi) enerji santralleri ülkemizde olduğu gibi birçok ülkede de kullanılmaktadır.

Yenilenebilir enerji kaynaklarından biri olan su, ülkemizde en çok enerji üretimi yapılan temiz enerji kaynağıdır. Özellikle nehir ve baraj hidroelektrik santraller temiz, güvenilir ve çevresel etkilerinin daha az olduğu enerji üretim santralleridir.

Doğu Karadeniz Bölgesi ülkemizde ki önemli su potansiyellerini içinde barındırmaktadır. $\mathrm{Bu}$ sebeple hem bölgesel hem de genel olarak enerji gereksinimlerimiz için kurulan hidroelektrik santraller bu bölgede de yer almaktadır.

Hidroelektrik santraller enerji kaynağı olarak suyu kullanmaktadırlar. Bu santraller mevcut suyun potansiyel enerjisini kinetik enerjiye çevirerek elektrik enerjisini üretirler. Genellikle nehir ve baraj santralleri olmak üzere ikiye ayrılır ve baraj santralleri rezervuar sisteminden oluştuğu için genellikle daha güvenilir, yüksek enerji potansiyeline sahiptir. Baraj yüksekliği ile oluşan rezervuar sayesinde suyun belirli bir yükseklikten düşürülmesi ile oluşan enerjiden faydalanılır. Bu sebeple düşü miktarı enerji üretiminde önemli bir faktördür. 
Hidroelektrik santrallerin en önemli faktörü olan su potansiyeli yağış verimi ile doğru orantılıdır. Bu santrallerin en büyük avantajı ise enerji üretim kaynaklarının yenilenebilir olması ve hammaddesi olan suyun enerji üretilmesi ile tükenmemesidir. Su kaynakları olarak akarsular önemli bir yer tutmaktadir.

Hidroelektrik santraller, diğer üretim tipleri ile kıyaslandığında en düşük işletme maliyetine, en uzun işletme ömrüne ve en yüksek verime haizdirler (Gökdemir ve ark., 2012).

Barajlar bir veya birden fazla amaca hizmet verebilmektedir. Bu amaçlar; enerji, sulama, taşkın, içme-kullanma suyu gibi sayılabilir. Ülkemizdeki barajların birçoğu enerji ve sulama amaçlarına hizmet vermektedir. Enerji amacı sadece baraj projeleri ile değil regülatörlü sistemler olan kanal ya da nehir tipi HES'ler ile de karş1lanabilmektedir.

Rezervuarlı yani depolamalı baraj santralleri mambasında oluşturdukları baraj gölleri sayesinde enerji için daha düzenli debi sağlamaktadır. Özellikle kurak sezonlarda yani yağıŞ miktarlarının daha düşük olduğu zamanlarda baraj rezervuarındaki su enerji için kullanılmaktadır. Yağışlı dönemlerde ise rezervuar dolacağı için enerji üretimi hemen hemen her mevsimde gerçekleşebilmektedir. Bu dönemler barajın emniyetli su rezervuarı oluşturdukları zamanlardır.

Depolamalı hidroelektrik santrallerde, zaman içinde rastgele bir değişken niteliğinde olan akım, depolama yapılmak suretiyle düzenlenmekte ve bu düzenli debiyle akarsudan elde edilen güvenilir enerji büyük ölçüde artmaktadır. Bu açıdan barajlar ülkemizde asla vazgeçilemeyecek tesislerdir (Dalkır ve Şeşen, 2011).

Baraj HES projelerinin projelendirme aşamalarında su potansiyeli dikkate alınarak yapılan optimizasyon çalışmaları neticesinde en uygun ortalama ve maksimum debi miktarı belirlenir. Maksimum debi aynı zamanda proje debisine de karşı1lık gelmektedir. Maksimum debi ve düşü yüksekliği baz alınarak kurulu güç, ortalama debi ve düşü yüksekliği ile de ortalama toplam enerji hesaplanmaktadır. Kurulu güç ve toplam enerji miktarlarına göre belirlenen kapasite faktörü ile HES projelerinin verimlilik değerlendirmesi yapılabilmektedir.

\section{Materyal ve Metot}

Baraj gölleri insanlar tarafından içme suyu eldesi, enerji üretimi ve sulama gibi amaçlarda kullanmak üzere, akarsuların önüne inşa edilen setlerin ardında toplanan durgun su kütleleridir (Özyalın ve Ustaoğlu, 2008). Barajların çoğu tek amaçlı barajlardır, ancak şu anda artan sayıda çok amaçlı baraj bulunmaktadır. Dünya Barajlar kayıtlarını en son yayınına göre sulama, barajların açık 
ara en yaygın amacıdır. Tek amaçlı barajların \%48' i sulama, \%17'si hidroelektrik (elektrik üretimi), \%13'ü su temini, \%10'u sel kontrolü, \%5'i rekreasyon ve \%1'den azı denizcilik ve balık çiftçiliği içindir (URL-1,2020).

Baraj projeleri ülkemizde enerji, sulama ve içme suyu amaçlarının yanı sıra taşkın koruma amacına da hizmet vermektedir. Özellikle havza bazlı projeler genellikle enerji üretim amaçlı olarak Doğu Karadeniz Bölgesi’nde yer almaktadır.

Baraj HES projelerinde kurulu güç ve toplam enerji üretim değerlerinin hesaplanması büyük önem arz etmektedir. Toplam enerji ve kurulu güce ait hesaplamalar şu şekilde yapılmaktadır (Acar, 2008).

Toplam enerji hesaplanırken, ortalama debi değeri kullanılır. Ortalama debi hesabında ise büyükten küçüğe sıralanan ve uzun yılları kapsayan günlük debilerin ortalaması alınır ve bu değer “ortalama debi” yi oluşturmaktadır.

Enerji hesaplamalarında güvenilir debi $\left(Q_{\text {güv }}\right)$ ve ortalama debi $\left(Q_{\text {ort }}\right)$ kullanılır. Aynı zamanda enerji hesabında türbin verimi ve jeneratör verimi yüzde (\%) olarak kullanılır. Bu verimler yer çekimi katsayısı olan $9,81 \mathrm{~m} / \mathrm{s}^{2}$ ile çarpılarak enerji katsayısı bulunur. Bu enerji katsayısı ile net düşü, debi ve bir yıldaki saat (365 gün x 24 saat = 8760) çarpılarak cinsinden yıllık enerji üretim değeri bulunmaktadır.

Enerji güç ile zamanın çarpımı, güç ise birim zamanda yapılan iş olarak tarif edildiğine göre bir hidrolelektrik santralden elde edilecek enerji aşağıdaki eşitlikler yardımıyla şöyle hesaplanabilir;

$\dot{I} s ̧=Q x \rho x H x t$

$G \ddot{u} c ̧=\frac{i s ̧}{z a m a n}=Q x \rho x H$

Buradaki debi $\mathrm{Q}\left(\mathrm{m}^{3} / \mathrm{s}\right)$, suyun özgül kütlesi $\rho\left(\mathrm{kg} / \mathrm{m}^{3}\right)$, düşü $\mathrm{H}(\mathrm{m})$, zamanı $\mathrm{t}(\mathrm{s})$ ise ifade etmektedir.

Suyun özgül kütlesi $\rho=1000 \mathrm{~kg} / \mathrm{m}^{3}$ ve $102 \mathrm{kgm} / \mathrm{s}=1 \mathrm{kw}$ olduğu göz önüne alındığında;

$G$ üç $=P(k w)=\frac{1000 x Q \times H}{102}=9,81 \times Q \times H$

ifadesi elde edilir. 
g: yerçekimi ivmesini temsil etmektedir ve değeri $9,81 \mathrm{~m} / \mathrm{s}^{2}$ ' dir.

Enerji, güç ile zamanın çarpımı olduğuna göre; yıllık enerji kwh cinsinden aşağıdaki formülle hesaplanır;

Enerji $=9,81 \times Q x H_{n e t} x 8760$ saat $/ y$ l

Bir hidroelektrik santralin üretebileceği enerji hesaplanırken türbin ve jeneratörün verimleri de yüzde olarak alınmaktadır. Bu durumda enerji denklemi aşağıdaki gibi olmaktadır;

Enerji $=9,81 \times Q x H_{n e t} x 8760 x$ türbin verimixjeneratör verimi

$\mathrm{Bu}$ ifadede debi $\mathrm{Q}_{\text {güv }}\left(\mathrm{m}^{3} / \mathrm{s}\right)$ için güvenilir enerji $\left(\mathrm{E}_{\text {güv }}\right)$ hesaplanmaktadır. Güvenilir enerji hesab1 için $\mathrm{Q}_{\text {güv }}$, toplam enerji $\left(\mathrm{E}_{\mathrm{top}}\right)$ hesabı için ise $\mathrm{Q}_{\text {ort }}$ ortalama debi değeri kullanılır. Burada güvenilir debi zamanın \% 95 inde akarsudan geçen olan debiyi ifade etmektedir.

İkincil ya da sekonder enerji, toplam enerjiden güvenilir enerji değeri çıkartılarak bulunur ve şu şekilde ifade edilir;

$E_{i k i n}=E_{t o p}-E_{g u ̈ v}$

Güvenilir debinin yüksek olması o projenin güvenilirliğini artırmaktadır. İkincil enerji olarak bulunan değer ise ortalama debi ile hesaplanan üretilen toplam enerjiden, güvenilir enerjinin çıkarılmasıyla bulunur.

Kurulu güç değeri kurulacak olan hidroelektrik santralin üretebileceği enerji için gereken gücü ifade eder ve en optimum debi ile hesaplanmaktadır;

Kurulu güç $=9,81 x Q_{\text {optimum }} x H_{\text {net }} x$ türbin verimixjeneratör verimi

Kurulu gücün birimi kW olarak hesaplanmaktadır.

Optimum debi projede optimizasyon yapılarak bulunmaktadır. Yani en ekonomik kanal ya da tünel kapasitesinin bulunması hedeflendiği için, hidroelektrik santral için kurulacak bütün tesislerin 
maliyetleriyle, debiye karşılık gelen kurulu güç değerleri ve enerji üretimleri arasında değerlendirme yapılarak bulunur.

Kurulu güç ve toplam enerjinin bulunması ile de kapasite faktörü (K.F.) belirlenebilmektedir.

Kapasite faktörü eşitlik 8'de ifade edilmiştir (Masters, 2004; Mathew, 2006; Arıkan ve Çam, 2012).

$$
K . F .=\frac{\text { üretilen toplam ener } j i}{\text { kurulu güç }(\text { K.G. }) \times 8760}
$$

Kapasite faktörü: bir enerji üretim sisteminin bir yıl içerisinde (8760 saat) toplam kaç saat tam güçte enerji verdiğini anlatır. Bir başka deyişle santralin bir yıl içerisinde üretmiş olduğu enerjinin, santralin bir yıl boyunca nominal güçte çalışarak üretebileceği enerjiye oranı kapasite faktörü olarak adlandırılır (Akkaş, 2001).

Kapasite faktörü genellikle Rüzgâr Enerji Santrallerinde (RES) bir enerji verimliliği hesabı olarak kullanılmaktadır. Fakat HES projelerinde de projenin rantabilitesini yani verimliliğini ortaya koyan en önemli etkenlerden biridir. Bu sebeple özellikle fizibilite raporunda projelerin kapasite faktörleri önemli bir yapılabilirlik göstergesidir.

Hidroelektrik enerji tesislerinin kapasite faktörleri diğer yenilenebilir enerji tesislerinden farklı olarak ele alınmalıdır. Bir nehir havzasındaki projeye esas alınacak akım değerleri oldukça değişken olabildiği gibi havzadan havzaya da farklılık gösterebilir. Bundan dolayı HES'lerin kapasite faktörlerinin değişim aralığı oldukça geniş olabilir (Yıldız ve ark., 2019).

\subsection{Doğu Karadeniz Bölgesindeki Baraj HES Projeleri}

Doğu Karadeniz Bölgesi Artvin, Rize, Trabzon, Bayburt, Gümüşhane ve Giresun illerini kapsamaktadır (Şekil 1). Bu bölge hem Karadeniz bölgesi için hem de ülke geneli için önemli su kaynaklarını barındırmaktadır. Bu sebeple birçok enerji üretim amaçlı hidroelektrik santral projeleri bu bölgede yer almaktadır. 


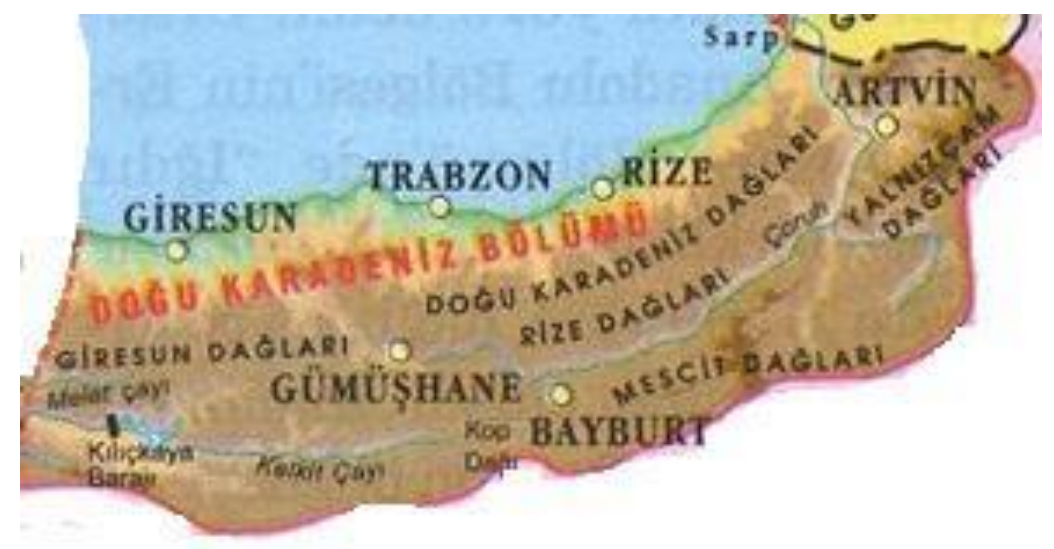

Şekil 1. Doğu Karadeniz Bölgesi

Ülkemizde su kaynaklarının kullanımı konusunda Devlet Su İşleri (DSI) Genel Müdürlüğü çalışmaktadır. Doğu Karadeniz Bölgesinde DSİ, 22. Bölge Müdürlüğü Trabzon ve 26. Bölge Müdürlüğü Artvin olarak hizmet vermektedir.

Trabzon Bölge Müdürlüğünün çalışma alanı; Trabzon, Rize, Bayburt, Gümüşhane ve Giresun illerini kapsamaktadır. Bu illerdeki işletmede olan Baraj HES projeleri Gümüşhane ve Trabzon illerinde olup, web sitesinden alınan bilgilere göre (URL-2, 2018);

Gümüşhane, Trabzon ve Artvin illerindeki Baraj HES projeleri Tablo 1.de verilmiştir.

Tablo 1. Baraj Hidroelektrik Santralleri

\begin{tabular}{|c|c|c|c|c|c|c|}
\hline Sira No & İli & Baraj Adı & $\begin{array}{c}\text { İnşaata } \\
\text { Başlanan } \\
\text { Yıl }\end{array}$ & $\begin{array}{l}\text { İşletmeye } \\
\text { Alındığı Yıl }\end{array}$ & $\begin{array}{l}\text { Kurulu Güç } \\
\text { (MW) }\end{array}$ & $\begin{array}{l}\text { Toplam } \\
\text { Enerji } \\
\text { (GWh) }\end{array}$ \\
\hline 1 & Gümüşhane & Kürtün Barajı & 1986 & 2003 & 85 & 198.00 \\
\hline 2 & Gümüsshane & Torul Barajı & 2000 & 2008 & 100 & 322.00 \\
\hline 3 & Trabzon & Atasu Barajı & 1998 & 2012 & 5 & 27.14 \\
\hline 4 & Artvin & Muratlı Barajı & 1999 & 2005 & 115 & 444.12 \\
\hline 5 & Artvin & Borçka Barajı & 1999 & 2007 & 300 & 1339.00 \\
\hline 6 & Artvin & Deriner Barajı & 1988 & 2012 & 670 & 2118.00 \\
\hline 7 & Artvin & Artvin Barajı & 2010 & 2016 & 332 & 1026.00 \\
\hline
\end{tabular}


Artvin Bölge Müdürlüğünün çalışma alanı; Artvin ilini kapsamaktadır. Bu ildeki işletmede olan Baraj HES projeleri (URL-3, 2018) web sitesinden alınmıştır.

\subsection{Baraj HES Projelerinin Kapasite Faktörleri}

Doğu Karadeniz Bölgesinde Gümüşhane, Trabzon ve Artvin illerindeki Baraj HES projeleri değerlendirildiğinde en çok enerji üreten projelerin Artvin İlinde olduğu görülmüştür. Bu mevcut projelerin kapasite faktörleri hesaplanmış ve Tablo 2.de verilmiştir.

Tablo 2. Baraj HES projelerinin kapasite faktörleri hesab1

\begin{tabular}{|c|c|c|c|c|c|}
\hline Sira No & İli & Baraj Adı & $\begin{array}{l}\text { Kurulu Güç } \\
\text { (MW) }\end{array}$ & $\begin{array}{c}\text { Toplam Enerji } \\
\text { (GWh) }\end{array}$ & $\begin{array}{l}\text { Kapasite } \\
\text { Faktörü }\end{array}$ \\
\hline 1 & Gümüşhane & Kürtün Barajı & 85.00 & 198.00 & $26,59 \%$ \\
\hline 2 & Gümüşhane & Torul Barajı & 100.00 & 322.00 & $36,76 \%$ \\
\hline 3 & Artvin & Muratlı Barajı & 115.00 & 444.12 & $44,09 \%$ \\
\hline 4 & Artvin & Borçka Barajı & 300.00 & 1339.00 & $\mathbf{5 0 , 9 5 \%}$ \\
\hline 5 & Artvin & Deriner Barajı & 670.00 & 2118.00 & $36,09 \%$ \\
\hline 6 & Artvin & Artvin Baraj1 & 332.00 & 1026.00 & $35,28 \%$ \\
\hline
\end{tabular}

\section{Bulgular ve Tartışma}

Kapasite faktörü bir projenin rantabilitesinin de bir ölçütüdür. Bu sebeple kapasite faktörü ne kadar yüksek olursa projenin mevcut kurulu gücünden çok daha fazla yararlanıldığı ve rantabilite değerinin de yüksek olduğu anlamına gelmektedir. Böylece bu tarz projelerin enerji üretim değerleri ile kapasite faktörleri arasında doğrusal bir ilişki olduğu sonucuna da varılmaktadır.

Değerlendirmede Gümüşhane İlinde bulunan Kürtün Barajı ve Torul Barajı ile Artvin İlinde bulunan Muratlı Barajı, Borçka Barajı, Deriner Barajı ve Artvin Barajı kullanılmıştır. Trabzon İlinde yer alan Atasu Barajının diğer barajlara göre kurulu güç ve toplam enerji değerlerinin düşük olmasından dolayı sağlıklı bir veri sağlamayacağı düşünüldüğünden değerlendirme dışı bırakılmıştır. 
Yapılan çalışmada kurulu güç değerleri maksimum kapasitedeki gücü ifade ettiği için toplam enerji üretim değerleri ile arasındaki ilişkinin birbirine yakın olması projelerin enerji verimliliği açısından optimum düzeyde olduğunu da göstermektedir. Bu sebeple kapasite faktörünün yüksek olması projelerin rantabil olması ile doğrudan ilişkilidir. Böylece hidroelektrik santral projelerinde de kapasite faktörü büyük önem arz etmektedir.

Doğu Karadeniz Bölgesinde yer alan projelerin Kurulu güç- Toplam Enerji grafiği Şekil 2.de verilmiştir. Bu durumda; Deriner Barajı en yüksek Kurulu Güç ve Toplam Enerji üretim değerine sahiptir.

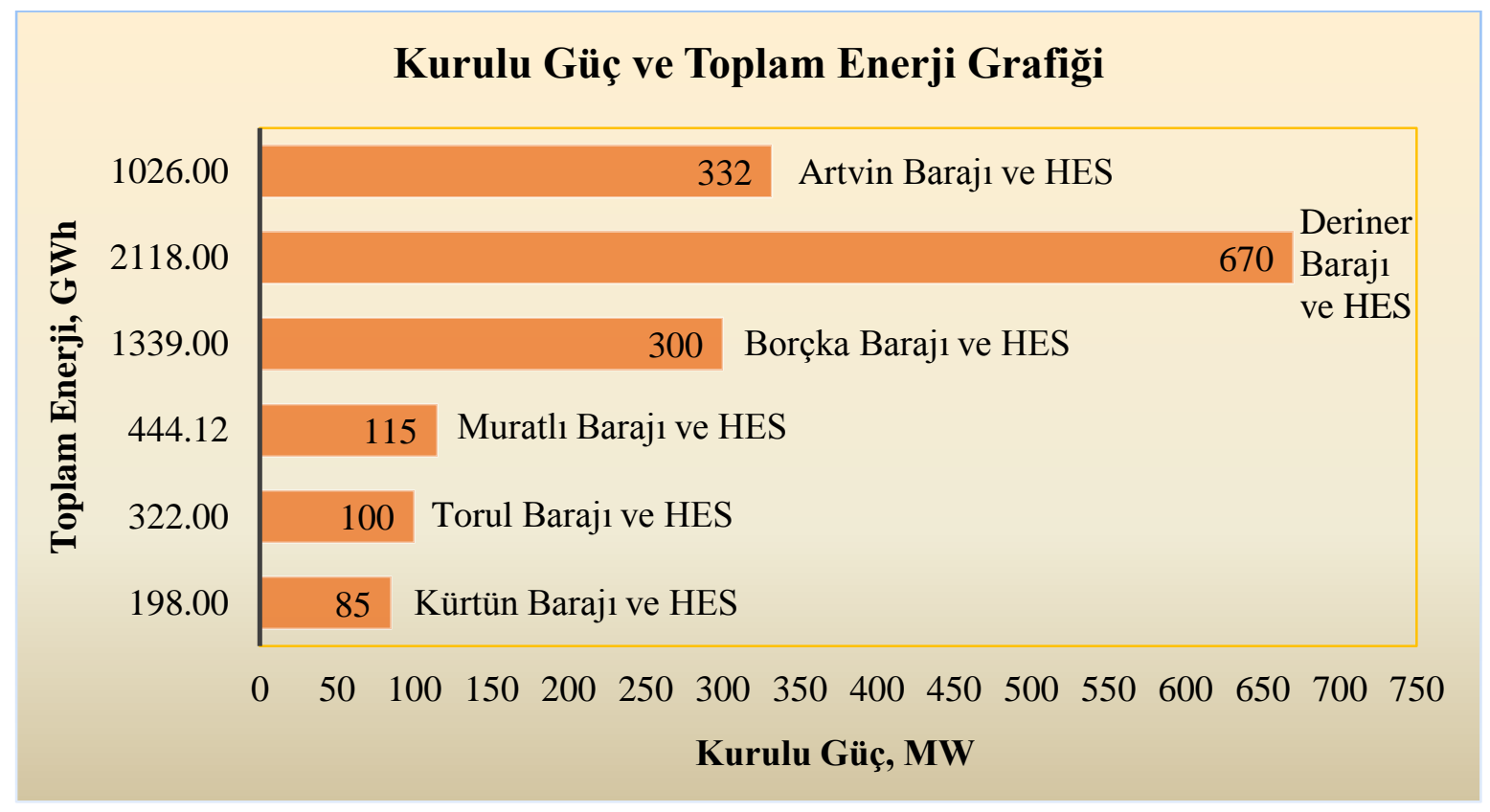

Şekil 2. Kurulu Güç ve Toplam Enerji Grafiği

Projelerin kapasite faktörlerine göre toplam enerji ilişkisi Şekil 3.te verilmiştir. Bu grafiğe göre Deriner Barajının en yüksek enerji üretim değerine sahip olmasına rağmen kapasite faktörü \%36,09 olup, $1339.00 \mathrm{Gwh}$ enerji üretim değeri ile Borçka Barajı ve HES projesi en yüksek kapasite faktörüne $(\% 50,95)$ sahiptir. 


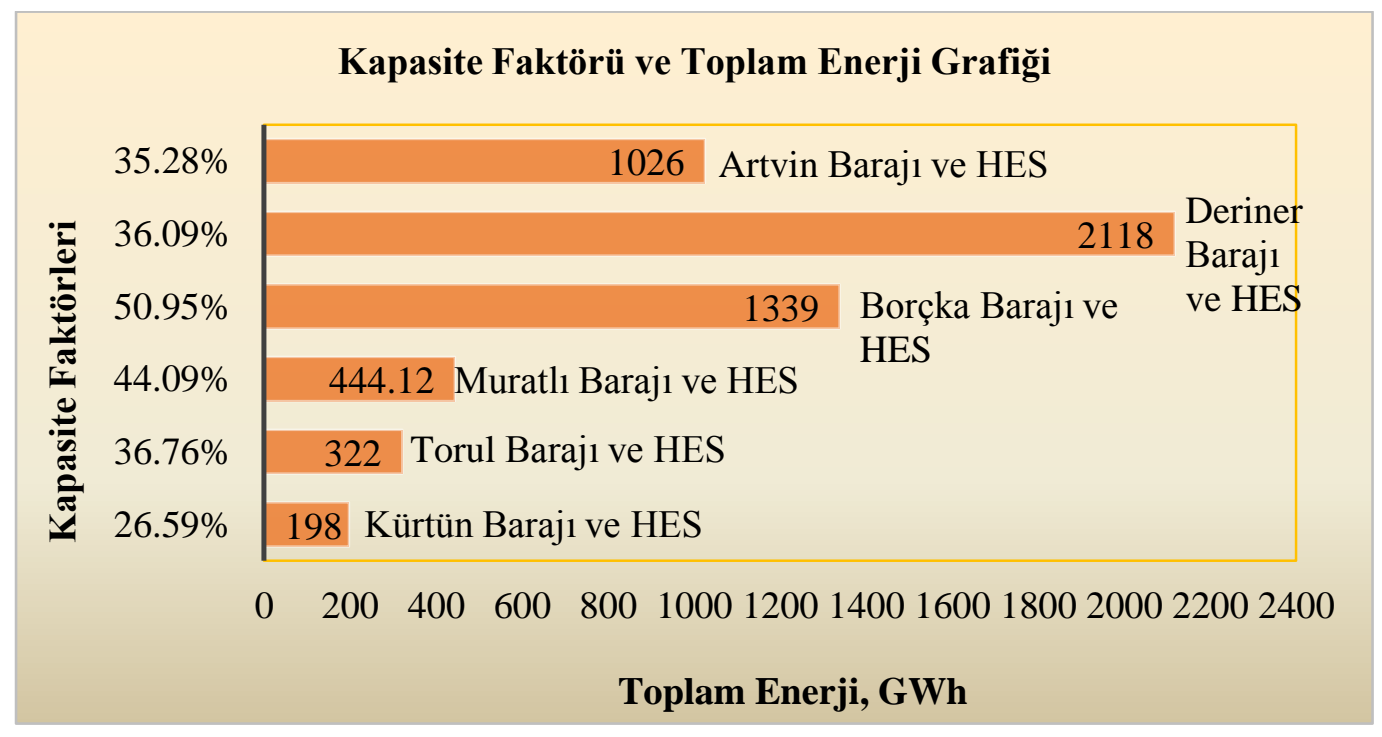

Şekil 3. Kapasite Faktörü ve Toplam Enerji Grafiği

Projelerin kapasite faktörlerine göre Kurulu Güç ilişkisi Şekil 4.te verilmiştir. Bu grafiğe göre 670.00 MW kurulu gücündeki Deriner Barajı ve HES projesi en yüksek kurulu güce sahip olmasına rağmen, $300.00 \mathrm{MW}$ kurulu gücündeki Borçka Baraj1 ve HES projesi en yüksek kapasite faktörüne sahiptir.

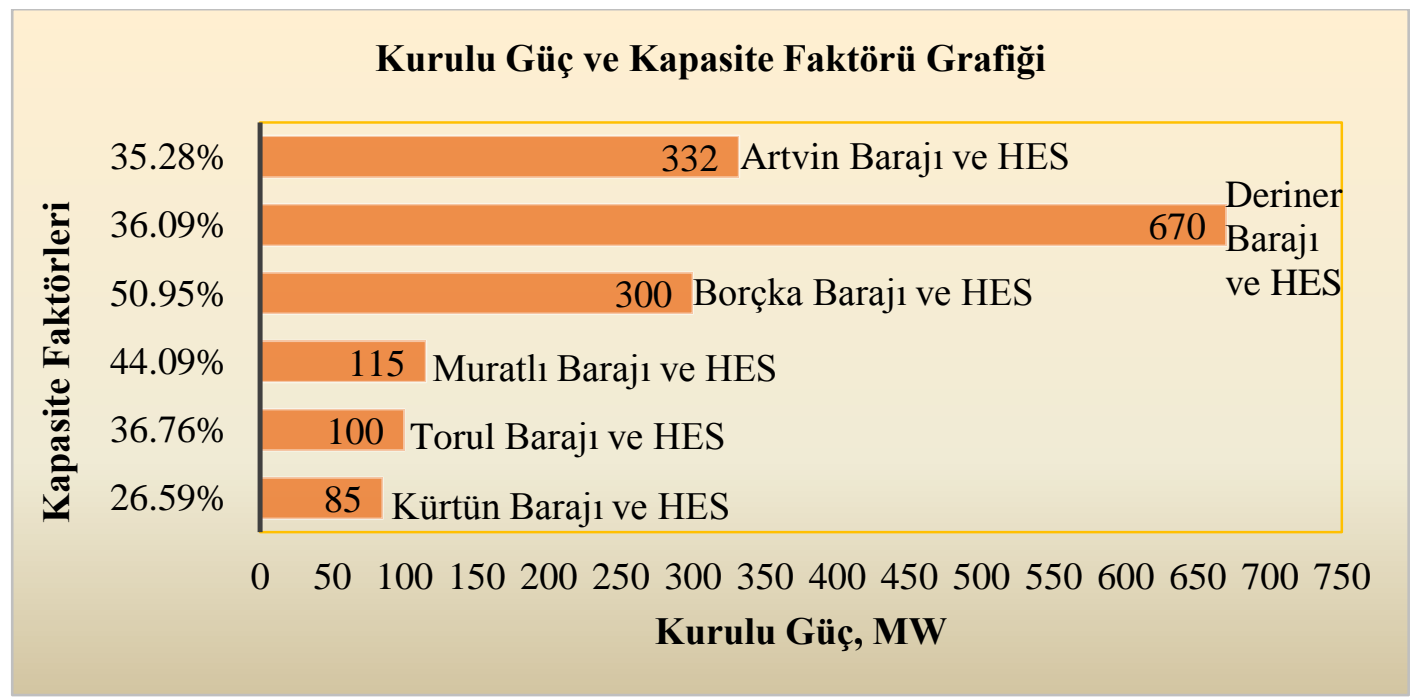

Şekil 4. Kapasite Faktörü ve Toplam Enerji Grafiği

Projelerin kapasite faktörlerine sırası ile Şekil 5.te verilmiştir. Bu grafiğe göre Borçka Barajı ve HES projesi en yüksek, Kürtün Barajı ve HES ise en düşük kapasite faktörüne sahiptir. 


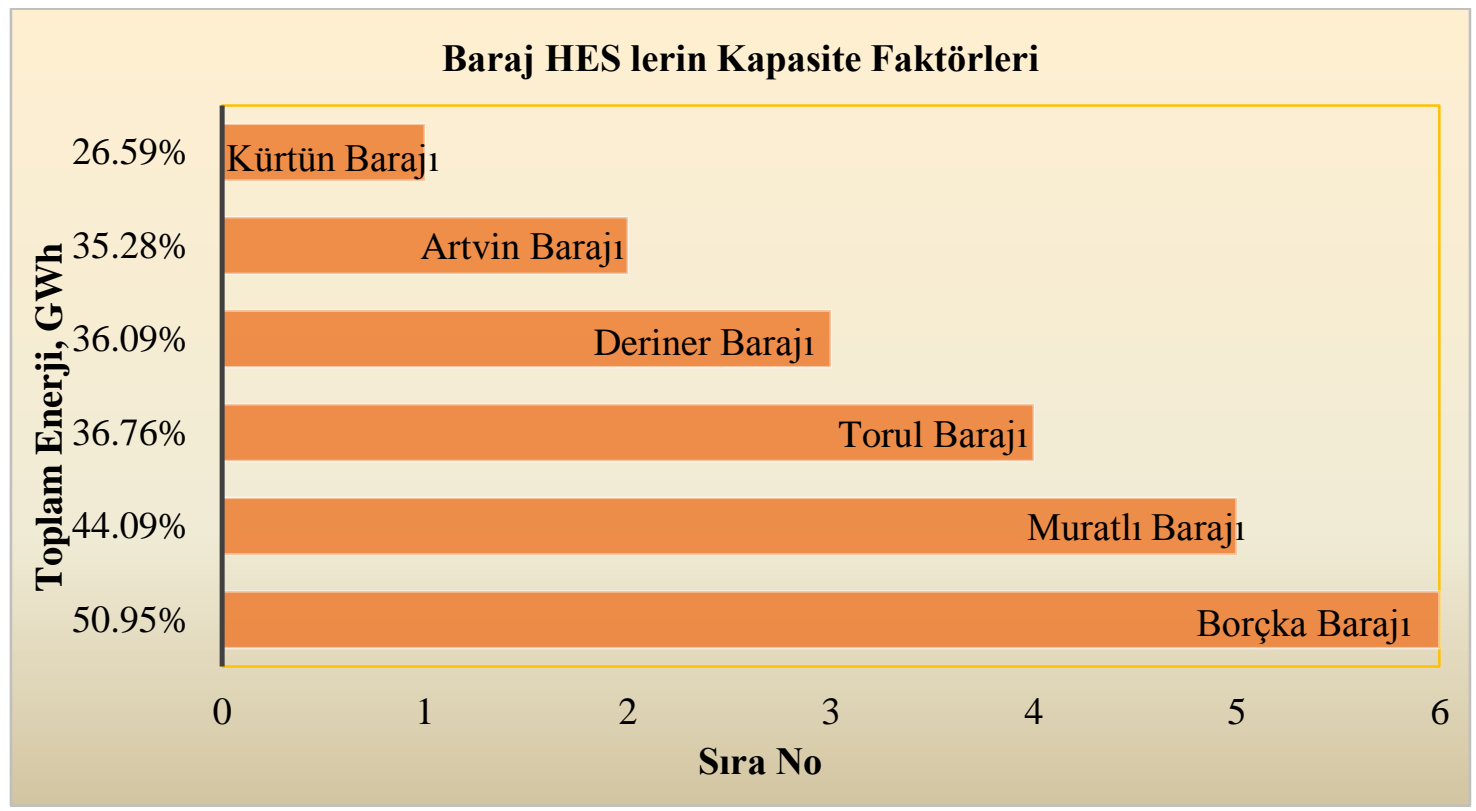

Şekil 5. Baraj Hidroelektrik Santrallerin Kapasite Faktörleri

\section{Sonuçlar ve Öneriler}

Sonuç olarak kapasite faktörü yalnızca kurulu güç ya da toplam enerji üretim değerine bağlı değildir. En yüksek kurulu güç ve enerji üretim değerlerine rağmen daha düşük kapasite faktörü çıkabilmektedir. Örneğin çalışmamızda en yüksek kurulu güç ve enerji üretim değeri olan Deriner Barajı ve HES projesinin kapasite faktörü \%36,09 iken daha düşük değerlere sahip Borçka Barajı ve HES projesi \%50,95 lik kapasite faktörü değerine sahiptir.

Borçka Barajı ve HES, mevcut kurulu gücünün yarısını kullanarak enerji üretebilmekte ve bu değerde oldukça yüksek bir değere tekabül gelmektedir. Ortalama \%30 luk kapasite faktörlerinin verimli projeler olarak değerlendirildiği analizlere göre bu değerin büyüklüğü aşikardır.

Borçka Barajının su potansiyelinin bu değere katkısı oldukça büyüktür. Aynı zamanda kapasite faktörünün yüksek değer olması bu projenin oldukça doğru bir yatırım olduğunun da göstergesidir. Genel itibari ile kapasite faktörlerinin \%30 seviyelerinde olan Doğu Karadeniz Bölgesindeki Baraj HES projelerinin ne kadar doğru ve verimli projeler olduğunu da ortaya koymaktadır.

Ülkemizde yer alan ve planlanan özellikle Baraj HES projeleri yüksek enerji üretimi yapan projelerdir. Kapasite faktörlerinin proje değerlendirmelerinde göz önünde bulundurularak optimum proje çözümlerinde bulunulması birçok projeyi yapılabilirlik açısından rantabil kılacaktır. Bu durum 
Acar, E., Uluslararası Doğu Anadolu Fen Mühendislik ve Tasarım Dergisi / International Journal of Eastern Anatolia Science Engineering and Design (IJEASED)

(2020) 2(2):296-307

mevcut kapasitesini daha çok kullanabilen projelerin verimlilik değerlerinin artacağı anlamına da gelmektedir. Örneğin karşılaştırma yapılacak olursa; ülkemizin önemli enerji kaynaklarından birisi olan Atatürk Barajı 2400 MW kurulu gücünde olup, 8400 Gwh yıllık enerji üretimi gerçekleşmektedir (URL-4) ve Atatürk Barajının kapasite faktörü \%26,97 dir. Doğu Karadeniz Bölgesinde yer alan Baraj HES ler değerlendirildiğinde de kapasite faktörlerinin \%26,59 ila \%50,95 aralığında olması önemli ve doğru yatırımlar olduğunun göstergesidir. Kapasite faktörlerinin yüksek olması ile su kaynaklarının da ne kadar güvenilir olduğu ve enerji üretiminin devamlılığı açısından da önemi vurgulanmaktadır.

\section{Teşekkür}

International Civil Engineering and Architecture Conference 2019, 17-20 April 2019, Trabzon/Turkey, Volume 1: Civil Engineering, page 854-860, ISBN: 978-605-81854-3-2 (Tk) 978605-81854-4-9 (1.c).

Konferansın gerçekleştirilmesinde katkı sağlayan tüm kurul üyelerine teşekkür ederim.

\section{Kaynaklar}

Acar, E. (2008). Türkiye'deki Rüzgâr ve Hidroelektrik Enerji Potansiyellerinin Karşılaştırılması ve Çevresel Etkilerinin Değerlendirilmesi. Yüksek Lisans Tezi, Eskişehir Osmangazi Üniversitesi, Fen Bilimleri Enstitüsü, Eskişehir.

Akkaş, A.A. (2001). Rüzgâr Enerjisi Sistemlerinin Performans Değerlendirmesi. Rüzgâr Enerjisi Sетроzуити (s.75-84).

Arıkan, Y., Çam, E. (2017). Rüzgâr ve Güneş Enerjisi Sistemlerinin Fizibilite Analizlerinin Web Tabanında Gerçekleştirilmesi. Uluslararası Mühendislik Araştırma ve Geliştirme Dergisi, 9(1), 1-10.

Dalkır, Ö. ve Şeşen, Ş. (2011), Çevre ve Temiz Enerji: Hidroelektrik, Ankara: Çevre ve Orman Bakanlı̆̆1 Devlet Su İşleri Genel Müdürlüğü.

Gökdemir, M., Kömürcü, M.İ. (2012). Türkiye'de Hidroelektrik Enerji ve HES Uygulamalarına Genel Bakış. İMO Su Yapıları Kurulu, TMH- 471, 18-26.

Mathew, S. (2006). Wind Energy Fundamentals, Resource Analysis and Economics. Netherlands: SpringerVerlag Berlin Heidelberg.

Masters, M. (2004). Renewable and Efficient Electric Power Systems. U.S.A.: John Wiley and Sons Publishers.

Özyalın, S, Ustaoğlu, M. (2008). Kemer Baraj Gölü (Aydın) Net Fitoplankton Kompozisyonunun İncelenmesi. Ege Journal of Fisheries and Aquatic Sciences, 25 (4), 275-282.

URL-1: https://www.icold-cigb.org/GB/dams/role_of_dams.asp, (Erişim Tarihi: 15.09.2020).

URL-2: http://bolge22.dsi.gov.tr/isletmedekitesisler/baraj-g\%C3\%B6let, (Erişim Tarihi: 22.06.2020).

URL-3: http://bolge26.dsi.gov.tr/isletmedekitesisler/baraj-g\%C3\%B6let, (Erişim Tarihi: 22.06.2020).

URL-4: http://www.dsi.gov.tr/projeler/ataturk-baraji, (Erişim Tarihi: 17.09.2020).

Yıldız, D., Yıldız D., ve Özgüler, H. (2019). Hidroenerji Raporu Yekdem'e Kayıtlı HES'lerin Üretim Verimliliği. $\mathrm{Su}$ Politikaları Derneği (SPD) Hidropolitik Akademi. Erişim: https://www.enerjiportali.com/wp-content/uploads/2019/07/YEKDEMe-Kay\%C4\%B1t1\%C4\%B1HESlerin-\%C3\%9Cretim-Verimlili\%C4\%9Fi.pdf 